\title{
Editorial
}

\section{Improving the quality of meals eaten or prepared outside the home}

In Western countries an increasing proportion of meals are being eaten outside the home, in restaurants, schools and from take-away stores ${ }^{(1)}$. From a public health perspective this development raises expectations as to the quality of foods served. In this issue we offer several papers that examine the ways in which stakeholders can be involved in planning and implementing changes in meal service and in the evaluation of meal services in schools and restaurants.

\section{Restaurant meals}

In order to increase sales and capture customer interest, restaurateurs seek to specialize, offering exceptional experiences and culturally unique culinary pleasures to their customers. Meanwhile, studies show that the meals offered are far from healthy or balanced and that their frequent consumption is linked with overweight and obesity $^{(2-4)}$. Even if going to a restaurant is a matter of personal choice, what the restaurant offers is dependent on the restaurateur. Public health nutritionists and other designers of public health interventions and training courses, together with policy makers, have a role in providing support and resources to promote changes in the provision of and demand for healthy meals in restaurants and other food establishments. The accessibility and availability of balanced meal options is all the more important when choice of restaurants is limited due to work or personal circumstances.

In this issue, Lachat et al. present findings from the HECTOR project, which examines participatory strategies to improve the nutritional value of meals eaten outside the home ${ }^{(1)}$. Results from stakeholder workshops suggest that a focus on healthy eating may necessitate trend setting and business reorientation, but this would pose financial risks, often not willingly taken. There is among restaurateurs a fear of losing customers by removing favourite dishes from the menu, and a loss of investment in the training of staff due to high turnover. While the willingness to participate is there, caterers put the onus on consumer-oriented awareness campaigns and supportive procedures to increase the demand for and supply of healthier, local and seasonal foods ${ }^{(1)}$.

Cross-sectional studies of the food offered or consumed in restaurants or canteens can identify associations between diet quality and the use of such food services, but cannot determine whether offering healthier food changes people's behaviour. A previous study from Finland $^{(5)}$ found that people who ate in school or staff canteens had better diet quality than those who did not, but this may reflect that people with better diets prefer to eat in canteens. However, even where nutritional recommendations, guidelines and government support for the catering services exist, guidelines are not always met and some form of monitoring is required. In Finland, nutrition policies have supported the improvement of institutional kitchens since the 1970s, but it was only last year that guidelines for the monitoring of quality were issued ${ }^{(6)}$.

\section{Intake of ready meals}

In this issue, a study of Swiss adults ${ }^{(7)}$ shows how lack of cooking skills was related to more frequent use of ready meals, defined as meals requiring few or no extra ingredients and designed to replace the main course of a home-made meal. Ready meals are typically high in energy, fat, salt and sugar, and have inadequate amounts of vegetables. In the Swiss study, ready-meal consumption was associated with overweight and a positive opinion about their nutritional content. The finding that ready-meal consumption was highest in the youngest age group (17-39-year-olds), may suggest a need to boost confidence in cooking skills and nutritional knowledge among those still at school and in training. Courses to that effect could also be offered as part of public health interventions and made relevant to people with limited time and cooking facilities. As suggested by the authors, more attention should be given to the composition of ready meals and the ways in which more vegetables could be included with such meals when served at home.

\section{School meals}

School breakfast and lunch programmes may help set an example for good food behaviours, as indicated by five studies in this issue; two from England ${ }^{(8,9)}$ and one each from New Zealand ${ }^{(10)}$, France ${ }^{(11)}$ and Wales ${ }^{(12)}$. The two English studies evaluated the quality of lunch meals provided and consumed in primary schools since the introduction of new standards aiming to ensure that all food and drink choices provided by school caterers are 'healthier' ${ }^{(8,9)}$. Both studies report that foods offered in 
schools were in line with the standards and that the composition had improved since their introduction ${ }^{(9)}$. Compared with lunches brought from home, school lunches were more nutrient-dense and adhered more closely to the standards ${ }^{(8)}$. In contrast to this, the New Zealand cross-sectional study ${ }^{(10)}$ suggests that in countries with no lunch provision at school, such as New Zealand, Australia and Denmark, children's nutritional intake during school days was less in line with the recommendations than during non-school days. In that study, $84 \%$ of the children reported that they brought most of the food consumed at school from home.

The French study of schoolchildren aged 3-17 years ${ }^{(11)}$ found that while $65.6 \%$ of children had a school lunch at least once weekly, children from more deprived economic backgrounds had more limited consumption of school lunches. Therefore moves to improve dietary intake among French schoolchildren through regulation of school lunch quality may not prove to be effective ${ }^{(11)}$. Increasing the number of children eligible for free or reduced-price meals may increase uptake in the lower socio-economic status groups, as has happened in the $\mathrm{USA}^{(13)}$.

As the school breakfast and lunch programmes aim to secure children's health, equal access to good nutrition and educational achievement, it is important to achieve high participation rates among children. In Wales, a study on the impact of a national school programme of universal free healthy breakfast provision demonstrated some improvement in the nutritional quality of breakfasts consumed in primary schools and a more positive attitude towards breakfast among children ${ }^{(12)}$. However, breakfast skippers did not start having breakfast, and no improvements were seen in episodic memory or classroom behaviour, the primary outcomes ${ }^{(12)}$. Interventions to increase the number of students participating in school food programmes may be more successful in achieving these outcomes.

The studies described here demonstrate the ongoing efforts to improve dietary intake by influencing the meals offered. However, it is not enough to develop recommendations and guidelines alone. These changes will need to be backed by programmes encouraging consumers to demand more healthy options. It is becoming clear that caterers require training to prepare and promote the new healthier choices; while schools have to support the future changes to meals with ongoing education ${ }^{(14)}$. For example, in the USA, the new (2010) guidelines and recommendations issued by Institute of Medicine ${ }^{(15)}$ to improve school meals reflect the commitment by state and federal governments to offer training and support for implementation, followed by monitoring of quality and fiscal action when necessary. As the proportion of food consumed outside the home continues to increase, it is essential that the nutritional quality be improved. There is no reason for food provided by food services to be of poorer quality than that provided at home. Indeed, the challenge will be to ensure that all food is made healthy, which requires changes in training, policy and provision.

Irja Haapala

Allison Hodge

Geraldine McNeill

Marilyn Tseng

Deputy Editors

Agneta Yngve

Editor-in-Chief

\section{References}

1. Lachat C, Naska A, Trichopoulou A et al. (2010) Essential actions for caterers to promote healthy eating out among European consumers: results from a participatory stakeholder analysis in the HECTOR project. Public Health Nutr 14, 193-202.

2. FOOD: A question of balance (2010) Fighting Obesity through Offer and Demand. http://www.food-programme. eu/en/ (accessed November 2010).

3. McCrory MA, Fuss PJ, Hays NP et al. (1999) Overeating in America: association between restaurant food consumption and body fatness in healthy adult men and women ages 19 to 80 . Obes Res 7, 564-571.

4. Burns C, Jackson M, Gibbons C et al. (2002) Foods prepared outside the home: association with selected nutrients and body mass index in adult Australians. Public Health Nutr 5, 441-448.

5. Raulio S, Roos E \& Prättäla R (2010) School and workplace meals promote healthy food habits. Public Health Nutr 13, 987-992.

6. Ministry of Social Affairs and Health (2010) Developing Mass Catering Services. Guidelines by the Working Group to Monitor and Develop Mass Catering Services. Helsinki: University Press.

7. van der Horst K, Brunner TA \& Siegrist M (2010) Readymeal consumption: associations with weight status and cooking skills. Public Health Nutr 14, 239-245.

8. Golley R, Pearce J \& Nelson M (2010) Children's lunchtime food choices following the introduction of food-based standards for school meals: observations from six primary schools in Sheffield. Public Health Nutr 14, 271-278.

9. Haroun D, Harper C, Wood L et al. (2010) The impact of the food-based and nutrient-based standards on lunchtime food and drink provision and consumption in primary schools in England. Public Health Nutr 14, 209-218.

10. Rockell JE, Parnell WR, Wilson NC et al. (2010) Nutrients and foods consumed by New Zealand children on schooldays and non-schooldays. Public Health Nutr 14, 203-208.

11. Dubuisson C, Lioret S, Dufour A et al. (2010) Socioeconomic and demographic variations in school lunch participation of French children aged 3-17 years. Public Health Nutr 14, 227-238.

12. Murphy S, Moore G, Tapper K et al. (2010) Free healthy breakfasts in primary schools: a cluster randomised controlled trial of a policy intervention in Wales, UK. Public Health Nutr 14, 219-226.

13. Probart C, McDonnell E, Hartman T et al. (2006) Factors associated with the offering and sale of competitive foods and school lunch participation. J Am Diet Assoc 106, 242-247.

14. Moore S, Murphy S, Tapper K et al. (2010) From policy to plate: barriers to implementing healthy eating policies in primary schools in Wales. Health Policy 94, 239-245.

15. Institute of Medicine, Committee on Nutrition Standards for National School Lunch and Breakfast Programs (2010) School Meals: Building Blocks for Healthy Children [VA Stallings, CW Suitor and CL Taylor, editors]. Washington, DC: National Academies Press. 